\title{
The Effect of Creating an Intervention in Children's Game Play and the Subsequent Minimization of Physical and Mental Damage
}

\author{
Ahmad Hammoud, Khodor Addam, and Nada Bukhari
}

\begin{abstract}
Children have become increasingly attached to smart devices as they become more ubiquitous in our society. Parents find themselves positioned between two extremes with no evidence of which may work. Taking a radical stance against device usage (whether absolute freedom or strict prohibition) does not work with children particularly. Yet, it is known that there are negative impacts from over usage. A mobile application has been developed to provide a moderated approach to this issue. The concept is to pause all games every few minutes and challenge the child with a question in Math, Science, or English related to their school curriculum. Children cannot keep playing unless they provide the correct answer and review their lessons in the process. In essence, this allows children continue to play on the condition that they review their lessons. Through this work, the concept of how children should perceive video gaming is changed. The outcome is to demonstrate to children that a tablet or smartphone is a privilege, not a right and that the price of the privilege is other activities including school work. In this article, the researchers have investigated the conditions of the usage of smart devices and devised a new solution that allows parents to minimize physical and mental damage while avoiding the extremes of freedom or prohibition. This was determined during an exercise that has been conducted on children playing games to measure their level of anxiety with and without the proposed solution to assess its efficiency. Four experts observed 40 children playing games and documented their reactions in terms of hyperventilation, abnormal movements, heartbeats, and blood pressure. The experiment included 2 parts. In part I, players kept playing for 30 minutes continuously without being interposed. In part II, players were interposed every 4 minutes and challenged with questions from their school curricula. The objective of the experiment is to check whether an intervention to the children every 4 minutes will lead to better physical and mental conditions.
\end{abstract}

Index Terms-Future of gaming, children's health, parental control, addiction to smart devices, games, education.

\section{INTRODUCTION}

Games are the most popular digital activity for children aged two to fourteen, with the highest usage penetration among mobile device users [1]. Recently, total App Store and Google Play app downloads amounted to more than 18.5 billion only in the second quarter of 2016 [2]. These markets could reach 2,200,000 apps and the number is increasing every day [3]. According to AppFigures, there are around

Manuscript received October 25, 2016; revised August 14, 2017. This work was supported by Global University and Play My Way.

The authors are with Global University, Batrakya, Beirut, Lebanon (e-mail: ahammoud@gmail.com,_draddam@hotmail.com, nadaboukhari@yahoo.com).
400,000 developers for the AppStore and 300,000 developers for Google Play. A total of 700,000 developers are spending their days developing mobile apps [4].

Currently, it is estimated that $22 \%$ of downloaded apps in 2015 from the AppStore and Google Play are games [5]. Table I shows the top category of downloaded apps from both stores.

TABLE I: THE TOP CATEGORY OF DOWNLOADS (2015)

\begin{tabular}{lll}
\hline \hline Rank & Store & $\%$ of total downloads \\
\hline 1 & App Store & $22.49 \%$ \\
1 & Google Play & $21.38 \%$ \\
\hline \hline
\end{tabular}

As Table I shows, "games" is always the top category of downloads. Furthermore, Lenhart, Kahne, Middaugh, Macgill, Evans, and Vitak stated that $97 \%$ of US teens play a certain type of digital game on regular basis [6].

This demonstrates how passionate users are to play games. Children are among those who are addicted to smart devices and want to play. According to NPD, 91 percent of U.S. children ages 2-17 play video games. "Year-to-date through August 2011, kids comprised 44 percent of new physical software dollar sales, representing a vitally important consumer segment for the games industry," said Anita Frazier, industry analyst. [7]. Victoria Woollaston states that one in three children are using tablets and phones before they can talk [8]. Children are becoming so addicted to smart devices and this is hurting them physically and mentally [9] [10], [11]. Kelly Wallace, CNN's digital correspondent, wrote: Half of teens think they are addicted to their smartphones [12].

These continuously increasing numbers place significant pressure on parents who are not happy with their children's addiction on smart devices. They know that smart technologies can benefit their children when used appropriately. However, there appears to be no moderate solution and current advice extends to giving in completely, or strict banning. Neither will work and presents significant longer term challenges. Thus, a compromise solution is needed. To provide such a solution, Dr. Hammoud developed a new app, called Play My Way, which works on top of other apps, creating an intervention to the game play or other operations to challenge children with questions related to their school curriculum. Children will not be able to resume their game unless they provide correct answers, which forces them to review their school material.

This means children are free to continue playing or updating their social media status on the condition that they review their lessons in the process. The core purpose is to get 
to a point where children understand that a tablet or smartphone is a privilege, rather than a right, and the price for that privilege is keeping up with studies [13]. Creating an automatic intervention to the child every now and then is not a radical stance. It is a win-win approach that allows the children to play, benefit from the device, keep up with new technologies, and review their lessons.

In this work, the researchers are trying to prove that interventions in the children's game play will result in better physical and mental conditions. When the children play for hours on their smart devices, they are hurt, as they remain anxious for a long time. Based on the researchers' experiment, the children's curve of anxiety keeps escalating when they are playing games. The question remains: if they experienced an intervention every 4 minutes, would this make them less anxious?

\section{PREVIOUS WORK}

Many studies have found a correlation between mobile games and mental / physical conditions. Calvert and Tan found that "students who had played a violent virtual reality game had a higher heart rate, reported more dizziness and nausea, and exhibited more aggressive thoughts in a posttest than those who had played a nonviolent game [14].

Irwin and Gross tried to identify effects of playing an aggressive vs. nonaggressive video game on second-grade boys identified as impulsive or reflective. Boys who had played the aggressive game, compared to those who had played the nonaggressive game, displayed more verbal and physical aggression to inanimate objects and playmates during a subsequent free play session [15].

A technical report by American Psychological Association confirmed link between playing violent video games and aggression [16]. Dr. Mark Appelbaum, who chaired the APA task force, said: "Scientists have investigated the use of violent video games for more than two decades but to date, there is very limited research addressing whether violent video games cause people to commit acts of criminal violence. However, the link between violence in video games and increased aggression in players is one of the most studied and best established in the field".

On the contrary, an Oxford University study suggests that playing violent video games is no more likely to be damaging to young children's behavior than those considered harmless [17].

Another study published by The Guardian newspaper (UK) found a weak association between the genre of game played at age 8/9, and conduct disorder band at age fifteen [18].

According to APA PsycNet, two studies examined violent video game effects on aggression-related variables. The first study found that real-life violent video game play was positively related to aggressive behavior and delinquency. Academic achievement was negatively related to overall amount of time spent playing video games. In he second study, laboratory exposure to a graphically violent video game increased aggressive thoughts and behavior [19].

Psychologist Douglas A. Gentile asserts that although violent games in particular can have negative consequences, well-designed games can teach positive skills. He proposes five attributes of video game design that can help explain findings and guide future research [20].

Anderson CA et al. used meta-analytic procedures to test the effects of violent video games on aggressive behavior, aggressive cognition, aggressive affect, physiological arousal, empathy/desensitization, and prosocial behavior [21].

It is obvious that this is an important research area, but the findings have never been conclusive. Some studies found a direct relationship between video games and children's behavior. Others don't confirm such a correlation.

The experiment that has been conducted in this research is different to what has been previously made. The researchers are trying to compare two scenarios:

- In the first scenario, the child plays a game continuously without experiencing an intervention. S/he keeps getting nervous and anxious as long as s/he is playing. After a while, the child might become so anxious because of the cumulative impact of the game.

- In the second scenario, the players experience an intervention every 4 minutes and asked a question. The objective of this intervention is to check whether stopping the children for 45 seconds will decrease their anxiety and cool them down for a while.

\section{Methodology}

\section{A. Materials and Methods}

This study comprises different techniques, methods, and procedures employed in gathering the needed data, such as the research design, respondents, sampling techniques, instruments used, administration, retrieval, and validation, as well as the treatment of data.

\section{B. The Sample}

The respondents addressed in the research were forty children between 5 and 11 years. Twenty-one males and nineteen females were randomly selected from various areas of Lebanon and different socio-economic levels. The respondents were asked to play games using Android devices while being observed by 4 experts.

\section{Research Design}

The study was cross-sectional. It was conducted to investigate if an intervention to the players every 4 minutes for around 45 seconds can decrease children's hyperactivity and anxiety caused by playing games on mobile phones.

\section{Study Protocol}

The experiment included two parts. In the first part, participants were required to play games on mobile phones for consecutive thirty minutes without stopping. In the second part, they experienced an intervention every 4 minutes and challenged by a question. Once, they provide the correct answer, they were allowed to proceed with playing. The game is designed to pause when "Home" key gets pressed and to resume once it is launched again.

\section{E. Inclusion Criteria}

Children who participated in the study know how to play games on mobile phones and are aged between 5 and 11 years inclusive. 


\section{F. Exclusion Criteria}

Excluded children are those who don't know how to play games / use mobile phone and those who are aged below 5 or above 11 .

\section{G. Data Collection Methods}

To gather the required data, the following 4 procedures were followed:

- Collecting Demographic Data: In order to build the respondents' profile, many pieces of information were collected, including gender, age, place of birth, place of living, and education level.

- Preparing Questions: Education specialists carefully prepared different questions related to the relevant academic curricula of the children.

- Experts' Selection: The experts were 3 groups: Technical experts who provided the technical support, Educators who led the different groups of children, and medical doctors who were observing \& evaluating the children while playing.

- The doctors used a special form to document data collected during their observation. The form is presented in Table II.

TABLE II: DOCTOR's OBSERVATION SHEET

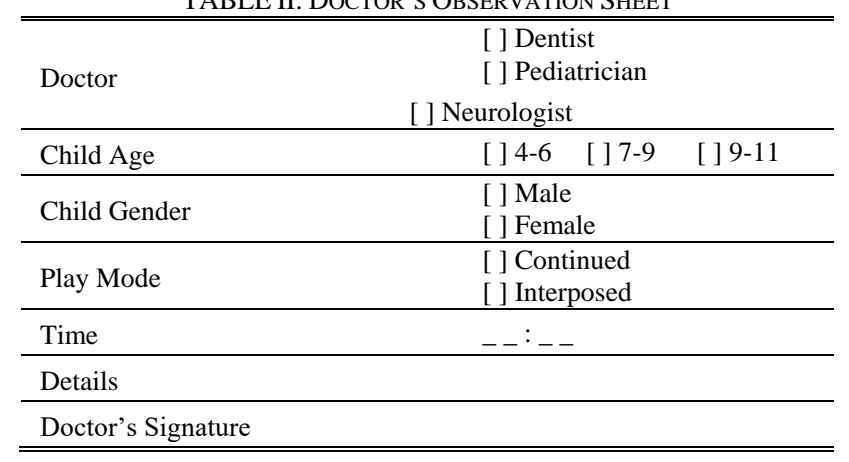

In order to measure the anxiety level of the children, the researchers decided to count how many signs of anxiety the child shows per minute. If a child, for example, did bite his/her lips 6 times in a minute, then s/he will score 6 points. If the same child showed less signs per minute because s/he was interposed every 4 minutes, the record anxiety level will be lower and the proposed solution would be considered successful.

\section{H. Description of the Experiment}

The experiment took place on Wednesday, October 12, 2016 between 3:00 PM and 5:00 PM. The forty children were invited to a small park for kids so they would feel at ease. They were accompanied with their parents who were sitting alongside them without any interference or influence. The children were divided into 5 groups on 5 tables. Every table had an expert that controls and manages the group. Every child was given an Android mobile phone with one game installed, called: BMX Boy. Several games had been checked, but the researchers wished to select a non-violent game that can let the children feel excited and motivated. The experiment includes two parts. In part I, the children were asked to start playing for 30 continuous minutes without being stopped or distracted. After a recess time of 10 minutes, part II started where they kept playing for another 30 minutes with one difference: they got interposed every 4 minutes and challenged to answer an educational question. Once they provide the correct answer, they resume playing. To motivate the children, they were asked to compete and told that each winner will be able to take the Android phone as a prize. As expected, they tried hard to win as they appreciate such a prize a lot.

\section{Results and Discussion}

Forty children were observed by three medical doctors:

- A dentist to check for any jaw tension or teeth grinding that might lead to headache and other problems.

- A pediatrician to check for any misbehavior and physical conditions.

- A neurologist to check for any tension, anxiety, or stress symptoms.

\section{J. First Part of the Experiment}

The doctors noticed that $75 \%$ of the participants showed most of the following symptoms while they were continuously playing games:

- Hypoventilation

- Sighing

- Elevation of shoulders

- Sweating

- Hyperactivity

- Shouting

- Crying

- Jumping / standing on the chairs

- Transversal movement of the mandibula

- Continuous biting of the lips

- Infrequent biting of the Buccal Mucosa (the inside lining of the cheeks)

- Infrequent squeezing of the lips with the fingers

- Abnormal movements, mainly in lower and upper extremities such as spastic movement of the leg / the hand, and cramp of the leg

- Continuous staring of the eyes on the game

- Euphoria (when winning a new game level)

- Having Rhinorrhea

- Having red faces

- Unrelaxed / aggressive facial expressions

- Tachycardia heart beat 110/minute. At the end of Part I, it was $115 /$ minute for two of them

As a matter of fact, the children did not show the above symptoms directly after they started playing, but rather gradually over time:

- Minute 0-7: The symptoms of anxiety and hyperactivity were weak. This could be due to the fact that the game is still at an easy level.

- Minute 8-18: The symptoms suddenly became noticeable

- Minute 19-30: The symptoms became strong and significant.

\section{K. Second Part of the Experiment}

At the end of Part I, the children were asked to rest for 10 minutes before commencing Part II They were then informed that they will experience an intervention every 4 minutes and requested to answer a question. 
The children started to play without any symptoms of hyperactivity or anxiety till the third minute. At the beginning of the forth minute, the symptoms of hyperactivity and anxiety began to appear, but this started to diminish when the children were requested to stop the game and answer a question.

TABLE III: DATA COLLECTED DURING OBSERVATION

\begin{tabular}{|c|c|c|}
\hline \multirow[b]{2}{*}{ Minute } & \multicolumn{2}{|c|}{ Signs per Minute } \\
\hline & Continued Mode & Interrupted Mode \\
\hline 1. & 0 & 0 \\
\hline 2. & 1 & 1 \\
\hline 3. & 2 & 2 \\
\hline 4. & 2 & 2 \\
\hline 5. & 2 & 1 \\
\hline 6. & 2 & 2 \\
\hline 7. & 3 & 2 \\
\hline 8. & 3 & 3 \\
\hline 9. & 3 & 2 \\
\hline 10. & 3 & 2 \\
\hline 11. & 4 & 3 \\
\hline 12. & 4 & 3 \\
\hline 13. & 4 & 2 \\
\hline 14. & 4 & 2 \\
\hline 15. & 4 & 3 \\
\hline 16. & 5 & 3 \\
\hline 17. & 5 & 2 \\
\hline 18. & 5 & 2 \\
\hline 19. & 5 & 3 \\
\hline 20. & 5 & 3 \\
\hline 21. & 6 & 2 \\
\hline 22. & 6 & 2 \\
\hline 23. & 6 & 3 \\
\hline 24. & 6 & 3 \\
\hline 25. & 6 & 2 \\
\hline 26. & 7 & 2 \\
\hline 27. & 7 & 3 \\
\hline 28. & 7 & 3 \\
\hline 29. & 7 & 2 \\
\hline 30. & 7 & 2 \\
\hline
\end{tabular}

When the children experienced an intervention every 4 minutes, this helped in reducing their level of anxiety, tension, and stress as monitored by the experts. Instead of applying cumulative pressure continuously on them, they experienced an intervention every 4 minutes which defused their anxiety, tension and stress. When challenged by a question on a regular basis, all the children passed through 3 stages:

- The first one is the blank stage. S/he is absent-minded and cannot answer a simple question such as: which day of the week is today? At this stage, the child seems like s/he needs up to 10 seconds to focus.

- The second stage is where the child is back and can understand the question. Most of anxiety symptoms disappeared within 7 seconds and the child was just waiting to answer the question in order to restart playing.

- In the third stage, the child is back to his/her normal stage. $\mathrm{S} /$ he understands the question and provides the correct answer.

Based on the researchers' observation, every stage needed 7 to 10 seconds for the majority of the children. This means that each child will spend 21 to 30 seconds to provide the correct answer. Once the child goes back to his/her favorite game, s/he needs around 20 seconds to become anxious again, which means that when experiencing an intervention the child calmed down for 41 to 50 seconds (the average is 45 seconds). This means that the child will receive a treatment for around 45 seconds every 4 minutes. This approach has 3 important outcomes:

- The child will calm down for almost $20 \%$ of the play time

- Whenever a child is about to go toward peaking with anxiety, s/he gets interposed by a question, and that automatically will calm him/her down.

- The child does some necessary actions. During the experiments, the doctors realized that 2 participants were not breathing normally while playing due to the tension. Their bodies were asking for oxygen because they are consuming Adrenaline but they are not breathing well to supply their bodies with what they need. When they are interposed with a question, they will breathe normally and supply their body with oxygen. Obviously, this stop is necessary to reset their malfunctioning body systems.

Doctors were recording how many times a child shows a sign of anxiety per minute. Teeth grinding, Jaw tension, and lips biting are examples of signs of anxiety. Data collected from both parts of the experiment is presented in Table III. The numbers shown in the last 2 columns of this table represent the average signs per minute of all participants. Children where stopped 7 times, indicated by shaded rows.

The graph that reflects the data shown in Table 3 is represented in Fig. 1.

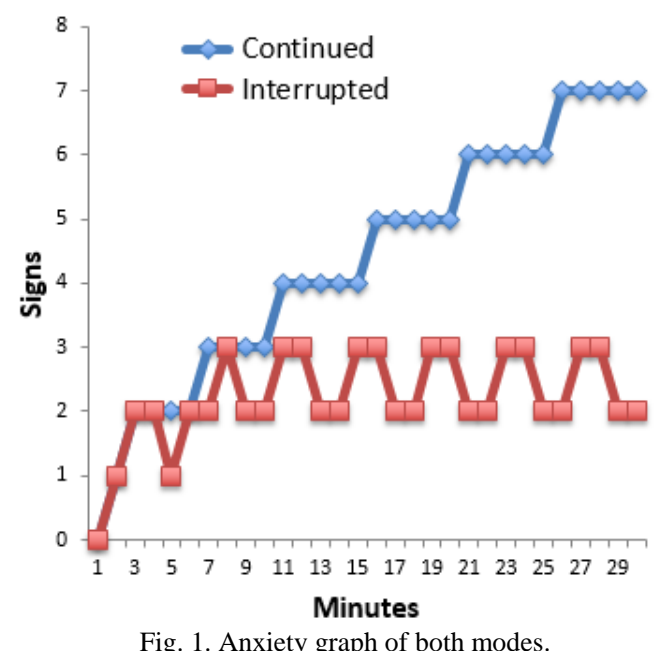

When the red curve slopes downwards, it means that the child is still anxious but with less symptoms.

As a separate note, the researchers realized the following:

- No child asked to go to the toilet, although the experiment took over an hour;

- No child asked for water; and

- All of them showed complete focus on the game despite parents and researchers in the environment.

\section{CONClusion}

The experiment showed that children who kept playing games without some form of intervention were more anxious than those who experienced an intervention every 4 minutes 
and were challenged with an educational question. This intervention has many advantages:

- It gives the children a chance to calm down;

- It makes them lose some anxiety instead of putting continuous pressure that accumulates on them;

- It will help them think of some necessary needs that they postpone otherwise. When the child's game is paused, $\mathrm{s} / \mathrm{he}$ realizes that $\mathrm{s} / \mathrm{he}$ has urgent needs such as breathing and peeing.

\section{RECOMMENDATIONS AND FUTURE WORK}

The researchers realized that observing 40 kids at the same time is challenging because every child can be a special case and needs special attention. When the next experiment is conducted, the following recommendations will be taken into consideration:

- Every child will be put alone in a separate room.

- A CCTV system will be used to monitor every child and record all of his/her reactions.

- The child's vital signs will be recorded. These include: heart rate and blood pressure. An EMG system might also be used to measure muscles activity.

\section{ACKNOWLEDGMENT}

We thank Dr. Colm Reilly, CEO of UK-Lebanon Tech Hub for his continuous support and his assistance for comments that greatly improved the manuscript. Special thanks also to the parents of the participants who filled, signed, and received a consent form to confirm their agreement on their child's deliberate voluntary participation in the study. Study conditions were explained to them..

\section{REFERENCES}

[1] L. Shoukry, C. Sturm, G. H. Galal-Edeen, and S. Göbel. (2014). Conducting evaluation studies of mobile games with preschoolers. DeLFI Workshops. [Online]. pp. 262-269. Available: https://www.statista.com/statistics/604343/number-of-apple-app-store -and-google-play-app-downloads-worldwide/

[2] Combined global Apple App Store and Google Play app downloads from 1st quarter 2015 to 2nd quarter 2016 (in billion). [Online]. Available:

https://www.statista.com/statistics/604343/number-of-apple-app-store -and-google-play-app-downloads-worldwide/

[3] Number of apps available in leading app stores. (June 2016). [Online]. Available:

https://www.statista.com/statistics/276623/number-of-apps-available-i n-leading-app-stores/

[4] Ariel. (January 2015). App stores growth accelerates in 2014. [Online]. Available:

http://blog.appfigures.com/app-stores-growth-accelerates-in-2014/

[5] R. Dogtiev. (2016). App store statistics roundup. [Online]. Available: http://www.businessofapps.com/app-store-statistics-roundup/

[6] A. Lenhart, J. Kahne, E. Middaugh., A. R. Macgill, C. Evans, and J. Vitak. (September 2008). Teens, video games, and civics. [Online]. Available:

http://www.pewinternet.org/Reports/2008/Teens-Video-Games-and-C ivics.aspx

[7] J. V. Camp. (2011). 91 percent of kids play video games, says study. [Online]. Available: http://www.digitaltrends.com/computing/91-percent-of-kids-play-vide o-games-says-study/

[8] V. Woollaston. (2013). The five signs your child is addicted to their iPad - and how to give them a 'digital detox'. [Online]. Available: http://www.dailymail.co.uk/sciencetech/article-2479109/The-signs-ch ild-addicted-iPad--digital-detox.html
[9] V. Ward. (October 2015). Children 'becoming hunchbacks' due to addiction to smart phones. The Telegraph. [Online]. Available: http://www.telegraph.co.uk/news/health/news/11935291/Children-bec oming-hunchbacks-due-to-addiction-to-smart-phones.html

[10] V. Ward. (April 2013). Toddlers becoming so addicted to iPads they require therapy. The Telegraph. [Online]. Available: http://www.telegraph.co.uk/technology/10008707/Toddlers-becoming -so-addicted-to-iPads-they-require-therapy.html

[11] K. Knull (September 2015). Over-use of iPads, iPhones and smart screens hurting kids. CBC news. [Online]. Available: http://www.cbc.ca/news/canada/edmonton/over-use-of-ipads-iphonesand-smart-screens-hurting-kids-1.3221491

[12] K. Wallace. (July 2016). Half of teens think they're addicted to their smartphones. CNN. [Online]. Available: http://edition.cnn.com/2016/05/03/health/teens-cell-phone-addiction-p arents/

[13] A. Baghdadi. (March 2016). Forget educational apps, check out education within apps. Arab Net. [Online]. Available: http://news.arabnet.me/education-apps-lebanon-parents-children-deve loper/

[14] C. Bernard. (November 1998). Video games: Research, ratings, recommendations. ERIC digest. ERIC clearinghouse on elementary and early childhood education champaign, IL. [Online]. Available: https://my.vanderbilt.edu/developmentalpsychologyblog/2014/04/effe ct-of-video-games-on-child-development/

[15] S. L. Calvert and S. L. Tan. (1994). Impact of virtual reality on young adults' physiological arousal and aggressive thoughts: Interaction versus observation. Journal of Applied Developmental Psychology. [Online]. 15(1). pp. 125-139. Available: http://files.eric.ed.gov/fulltext/ED424038.pdf

[16] American Psychological Association. (2015). APA review confirms link between playing violent video games and aggression [Online]. Available:

http://www.apa.org/news/press/releases/2015/08/violent-video-games aspx

[17] J. Bingham. (April 2015). Study finds no evidence violent video games make children aggressive. The Telegraph. [Online]. Available: http://www.telegraph.co.uk/science/2016/03/12/study-finds-no-eviden ce-violent-video-games-make-children-aggres/

[18] P. Etchells. (February 2016). Is there an association between video games and aggression? The Guardian. [Online]. Available: https://www.theguardian.com/science/head-quarters/2016/feb/12/viole nt-video-games-aggression-a-complex-relationship

[19] C. A. Anderson and K. E. Dill. (2000). Video games and aggressive thoughts, feelings, and behavior in the laboratory and in life. Journal of Personality and Social Psychology. [Online]. 78(4). pp. 772-790. Available: http://psycnet.apa.org/journals/psp/78/4/772/

[20] D. Gentile. (July 2009). Video games affect the brain - for better and worse. [Online]. Available: http://www.dana.org/Cerebrum/2009/Video_Games_Affect_the_Brai $\mathrm{n}$-for_Better_and_Worse/

[21] C. A. Anderson, "Violent video game effects on aggression, empathy, and prosocial behavior in eastern and western countries: A meta-analytic review," US National Library of Medicine National Institutes of Health, vol. 136, no. 2, pp. 151-73, March 2010.

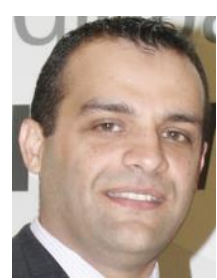

Ahmad Hammoud was born in 1972. He is a pracademic with compelling drive for and interest in conveying the knowledge he has acquired in both academia and corporate over the past 20 years. He has been granted a $\mathrm{PhD}$ in computer science in 2011 by Telecom University in Bretagne, France. He has published several papers and has spoken in several international conferences in Europe, Asia, Australia, and in the Middle-East. He developed enterprise apps for many international institutions, including UN and World Bank. He taught advanced computer courses in many universities. He is the head of the research unit at Global University, the chairperson of Scope for IT services, and the founder of PlayMyWay app. He is also the proud author of two books, one of which received the Best-Seller award at Biel in 2013. He has conducted several research endeavors around education. He takes particular satisfaction in liaising between schools, universities, and private organizations around this "cause". He is also a member of the International Advisory Board of the International Conference on Education and New Learning Technologies. $\mathrm{He}$ has also gain sound momentum in Internet security, and has been able to organize several public events over the years. 


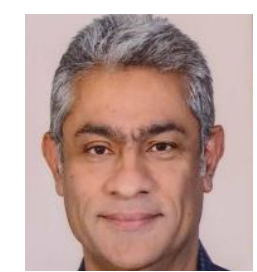

Khodr Addam graduated with a Bachelor's of Somatology (DDS) from Plovdiv, Bulgaria in 1988. Since then, Dr. Addam has earned a Ph.D. of Nutrition and Dietetics from the University of NAPC Chekia - Prague (2003), an honorary diploma from NAPC University - England (2004), a Bachelor in Business Administration from BCU University Lebanon (2007), and an MBA from AUL University Lebanon (2011). Dr. Addam is a certified member in the "Lebanese Dental Association, and has been practicing dentistry since 1989. He has lectured and continues to lecture at several universities (NAPC University - Prague, Hawaii University - Lebanon, BCU University - Lebanon, Global University - Lebanon, NAPC University - England). He is a member of the Lebanese Dental Syndicate since 1991, the vice president of the Environmental Care Office in AUL since 2002, head of Research Center for Medicinal Herbs and Environmental Studies at Global university 2005-2009, member of the Lebanese Physical Cultural Association 2000-2008, member of the Medical
Committee of the Arab Physical Cultural Federation 2000, member of the research center in AUL, and founder of Dr. Addam's Herbarium In AUL. He has also been published in several journals and has organized and spoken at many conferences and workshops.

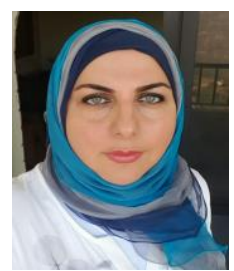

Nada Bukhari graduated from the Medical School of the University of Damascus in 1994. She then joined the American University of Beirut and graduated as a Pediatrician Neothologist in 1998. Since then, she has been treating patients in her private clinic, Najjar Private Hospital, and Zahraa University Hospital. Dr Bukhari is a lecturer at Global University since 2003 and is responsible for senior projects in the Nursing School. During her nearly 20 years of experience, Dr. Bukhari has participated in many conferences, organized several academic events, and delivered tens of workshops. 